\title{
Pemberian Makanan dengan Frekuensi Sesuai dan Beragam Merupakan Salah Satu Kunci Status Gizi Normal pada Baduta yang Memiliki Riwayat BBLR di Kota Bogor (Studi Kualitatif di Kecamatan Bogor Tengah)
}

\author{
Appropriate Frequency and Diverse Complementary Feeding As the Keys of Normal Nutritional Status \\ on Low Birth Weight Children in Bogor City (Qualitative Study in Central Bogor District)
}

Indri Yunita Suryaputri*, Nurilah Amaliah, Bunga Ch Rosha, dan Kencana Sari

Pusat Penelitian dan Pengembangan Upaya Kesehatan Masyarakat, Badan Penelitian dan Pengembangan Kesehatan, Kementerian Kesehatan RI, Jl. Percetakan Negara No. 29 Jakarta Pusat, Indonesia Korenspondensi Penulis : indri.ysp@gmail.com

Submitted: 09-06-2018; Revised: 13-08-2018; Accepted: 05-09-2018

DOI: https://doi.org/10.22435/mpk.v28i3.233

\begin{abstract}
Abstrak
Tingkat morbiditas dan mortalitas bayi di Indonesia masih tinggi. Faktor yang menjadi salah satu penyebab kematian neonatus ialah Bayi Berat Lahir Rendah (BBLR). Oleh karena itu, mengetahui praktik Inisasi Menyusui Dini (IMD) dan pemberian Air Susu Ibu (ASI) esklusif serta pola pemberian makan pada bayi di bawah dua tahun (baduta) dengan status gizi normal yang mempunyai riwayat BBLR sangatlah penting. Penelitian ini merupakan penelitian kualitatif bagian dari penelitian kohor tumbuh kembang anak (TKA) tahun 2017 di Kota Bogor. Penelitian dilakukan dengan cara wawancara mendalam terhadap 12 informan ibu yang memiliki anak baduta dengan status gizi normal (BB/U dan BB/TB) yang pada saat lahir mempunyai riwayat berat badan lahir rendah. Hasil penelitian menunjukkan bahwa sebagian besar informan tidak melakukan IMD. Namun pada praktik pemberian makanan memperlihatkan bahwa frekuensi pemberian makan kepada anak cenderung sesuai dengan anjuran dari WHO. Promosi dan edukasi amat perlu dilakukan pada ibu dan keluarga untuk mendukung keberhasilan praktik IMD, pemberian ASI eksklusif, pemberian makanan dengan frekuensi sesuai dan beragam pada anak BBLR.
\end{abstract}

Kata kunci: Inisiasi Menyusui Dini; ASI eksklusif; keragaman makanan; frekuensi makan.

\begin{abstract}
The level of infant mortality and morbidity in Indonesia is still high. The factor that is one of the causes of neonatal death is Low Birth Weight (LBW). Therefore, knowing the practices of early initiation breast feeding, exclusive breast feeding, and child feeding of children with normal nutritional status who have low birth weight history is very important. This research is a qualitative study part of growth and development cohort study held in Kota Bogor in 2017. In-depth interviews were conducted to 12 informants of mothers who have children with normal nutritional status (WAZWHZ) who at birth had a history of low birth weight. The results showed that most of the informants did not practice early breast-feeding initiation. However, the practice of feeding shows that the frequency of feeding to children tends to be in accordance with recommendation from the WHO. Promotion and education are very necessary to be done for mothers and families to support the success of initial breast feeding practices, exclusive breast-feeding appropriate and varied frequency for low birth weight children.
\end{abstract}

Keywords: early initiation of breast feeding; exclusive breastfeeding; food frequency; food diversity. 


\section{PENDAHULUAN}

Indonesia sebagai salah satu negara berkembang masih memiliki tingkat morbiditas dan mortalitas bayi yang masih tinggi. Berdasarkan data Survei Demografi dan Kesehatan Indonesia (SDKI) pada tahun 2017, angka kematian neonatal sebesar 15 per 1.000 kelahiran hidup, angka ini sempat stagnan pada tahun 2007 ke 2012 namun di tahun 2017 mengalami penurunan. ${ }^{1}$ Faktor yang menjadi salah satu penyebab kematian neonatus ialah bayi berat lahir rendah (BBLR). ${ }^{2}$ Pengertian BBLR ialah bayi yang dilahirkan dengan berat kurang dari 2.500 gram, tanpa melihat umur bayi dalam kandungan. Indonesia memiliki prevalensi kelahiran bayi dengan berat lahir rendah atau BBLR sebesar 10,2\% berdasarkan Riskesdas tahun 2013. ${ }^{3}$

Lahir dengan berat lahir rendah merupakan hal yang merugikan bagi bayi. Bayi dengan berat lahir rendah memiliki risiko lebih tinggi untuk mengalami kegagalan tumbuh, keterlambatan perkembangan, mudah terkena infeksi dan peluang lebih besar untuk mengalami sakit, serta kemungkinan bertahan hidup yang lebih rendah. ${ }^{4}$ Selain itu, BBLR dapat juga berkaitan dengan penyakit tidak menular saat dewasa. ${ }^{5}$ Oleh karena itu, upaya untuk menurunkan angka kematian bayi serta meningkatkan kualitas kesehatan anak sejak dini melalui penurunan angka BBLR sangatlah penting.

World Health Organization (WHO) merekomendasikan antara lain memberikan inisiasi menyusu dini, Air Susu Ibu (ASI) ekslusif, ASI hingga umur 2 tahun, serta makanan pendamping ASI yang beragam. ${ }^{6}$ Pemberian ASI eksklusif untuk bayi 0-6 bulan ini juga ditekankan dalam Peraturan Pemerintah Nomor 33 tahun 2012 tentang Pemberian Air Susu Ibu Eksklusif.7

Pemberian ASI eksklusif yang benar, keberlangsungan pemberian ASI, dan pola makan yang baik diharapkan dapat membantu anak dengan berat lahir yang rendah untuk mencapai pertumbuhan secara optimal. Pada bayi, ASI amat berperan dalam pemenuhan gizinya, selain itu ASI juga meningkatkan kekebalan tubuh bayi dari ancaman penyakit infeksi. Sebuah penelitian longitudinal di India terhadap 54 bayi dengan berat badan kurang dari 2.500 gram memperlihatkan bahwa pada bayi-bayi yang diberi ASI secara eksklusif mengalami kenaikan berat badan, lingkar kepala dan panjang badan yang hampir sama dengan bayi yang dilahirkan dengan berat badan normal. ${ }^{8}$ Penelitian yang dilakukan terhadap 204 ibu dengan anak BBLR yang diikuti sejak lahir hingga berusia 6 bulan setelah melahirkan memperlihatkan bahwa anak yang memperoleh ASI eksklusif tidak mengalami diare dibandingkan dengan anak yang tidak menerima ASI eksklusif, anak yang ASI eksklusif juga juga lebih jarang mengalami infeksi pernapasan. ${ }^{9}$

Hasil lain yang sejalan juga terlihat pada penelitian terhadap 300 bayi baru lahir dengan berat badan kurang dari 2.500 gram, yaitu bayi dengan berat lahir rendah yang diberi ASI secara eksklusif memiliki kenaikan berat badan yang signifikan dibandingkan dengan yang tidak diberi ASI secara eksklusif, selain itu angka kesakitan juga berkurang drastis pada morbiditas bayi dengan berat lahir rendah yang diberi ASI eksklusif. ${ }^{10}$ Sejalan dengan hal ini, penelitian di Hongkong menunjukkan bahwa pemberian ASI pada bayi BBLR memiliki Z score pertumbuhan yang lebih baik dibandingkan dengan bayi yang diberi susu formula. ${ }^{11}$

Pada kejadian BBLR, salah satu penyumbang utama kematian ialah pemberian ASI yang tidak adekuat. ${ }^{12}$ Hubungan antara pemberian ASI yang tidak cukup dengan kematian bayi akibat BBLR ialah bahwa ASI merupakan faktor pelindung yang memberikan imunitas secara langsung kepada bayi untuk melawan penyakit infeksi sehingga jika bayi yang mengalami BBLR tidak diberikan ASI secara eksklusif maka kemungkinan terkena infeksi sangat besar. Namun demikian angka pemberian ASI eksklusif di Indonesia masih rendah. Proporsi menyusui eksklusif di Indonesia pada bayi usia 4-5 bulan sebesar 38,2\%, angka ini memperlihatkan bahwa satu dari tiga bayi di bawah usia enam bulan diberi ASI eksklusif. ${ }^{1}$ Black et a ${ }^{13}$ mengungkapkan bahwa pemberian ASI optimal di bawah usia 2 tahun memiliki dampak terbesar pada kelangsungan hidup anak dengan potensi mencegah $13 \%$ dari semua kematian pada anak di bawah 5 tahun.

Keberhasilan menyusui eksklusif dimulai dari proses Inisiasi Menyusui Dini (IMD). Berdasarkan hasil penelitian terhadap 243 ibu yang memiliki anak usia 12-24 bulan yang diwawancara menggunakan kuesioner di Subang, Jawa Barat, memperlihatkan IMD berhubungan secara signifikan dengan pemberian ASI secara eksklusif. ${ }^{14}$

Selain pemberian ASI eksklusif dan keberlangsungan menyusui, faktor lain yang juga penting bagi anak ialah pola pemberian makan yang benar dalam rangka meningkatkan berat badan terutama pada anak dengan riwayat BBLR. Proses peningkatan berat badan ini merupakan 
proses yang tidak terjadi dalam waktu singkat dan dilakukan secara bertahap sesuai dengan usia bayi. Peningkatan berat badan yang cukup dapat membuat anak dengan riwayat BBLR mengejar pertumbuhan dan perkembangan agar sesuai dengan anak yang lahir dengan berat lahir normal. ${ }^{15}$

Penelitian mengenai BBLR dan faktor determinan yang berkaitan dengan BBLR sudah cukup banyak namun penelitian kualitatif yang menggali mengenai praktik IMD, pemberian ASI serta pola pemberian makan pada anak BBLR belum banyak dilakukan. Penelitian ini ingin mengetahui gambaran praktik IMD, pemberian ASI dan pola pemberian makan anak baduta dengan status gizi normal yang memiliki riwayat BBLR di Kota Bogor.

\section{METODE}

Penelitian ini merupakan bagian dari penelitian kohor Tumbuh Kembang Anak (TKA) yang bertujuan untuk memperkaya informasi yang belum diperoleh dari data kuantitatif. Penelitian kualitatif Kohor TKA tahun 2017 mengambil tema tentang pengasuhan anak dengan riwayat BBLR dan menghasilkan subtema praktik IMD, menyusui dan pemberian makan baduta dengan riwayat BBLR dalam mencapai pertumbuhan berat badan normal. Subtema lainnya ialah perihal pengetahuan ibu mengenai BBLR dan cara menghangatkan bayi BBLR yang masih dalam proses penerbitan pada jurnal ilmiah nasional.

Definisi yang digunakan dalam penelitian ini merujuk pada definisi WHO mengenai IMD, pemberian ASI eksklusif dan pemberian makan anak usia 6-23 bulan. IMD adalah meletakkan bayi di dada atau perut ibu secara tengkurap sehingga kulit bayi dan kulit ibu melekat dilakukan sekurang-kurangnya satu jam segera setelah lahir, kemudian pengertian ASI eksklusif adalah pemberian ASI saja sejak lahir sampai usia anak 6 bulan, sedangkan pola pemberian makan ialah pemberian makan anak usia 6-23 bulan sejumlah 4 atau lebih kelompok makanan dari 7 kelompok makanan pada waktu 24 jam sebelumnya ${ }^{6}$ Tujuh kelompok makanan yang dimaksud ialah bijibijian dan umbi-umbian, kacang-kacangan, susu dan produk susu (susu, yoghurt, keju), dagingdagingan (daging, ikan, unggas, dan jeroan), telur, sayur dan buah sumber vitamin A, sayur dan buah lain.

Penelitian dilakukan dengan cara wawancaramendalamterhadapinformanyangtelah ditentukan oleh peneliti. Wawancara dilakukan saat anak berusia di bawah dua tahun (baduta), untuk mengurangi kemungkinan hilangnya informasi yang disebabkan keterbatasan ingatan informan maka diajukan beberapa pertanyaan yang berbeda namun bertujuan menjawab subtema yang sama. Etik penelitian ini menginduk kepada surat izin etik penelitian Kohor TKA, karena merupakan bagian dari penelitian tersebut dengan nomor etik LB. 02.01/2/KE.108/2017.

Penentuan informan menggunakan teknik non probability sampling, yaitu purposive sampling yang dipilih tanpa acak dan didasarkan pada suatu pertimbangan tertentu yang dibuat oleh peneliti yaitu berdasarkan ciri atau sifatsifat populasi yang telah diketahui. Informan merupakan responden penelitian Kohor TKA.

Kriteria inklusi informan adalah ibu yang memiliki anak usia baduta dengan status gizi normal berdasarkan berat badan menurut umur $(\mathrm{BB} / \mathrm{U})$ dan berat badan menurut tinggi badan $(\mathrm{BB} /$ TB) serta mempunyai riwayat BBLR. Informasi mengenai data berat badan lahir diperoleh melalui dokumen kesehatan anak. Sedangkan kriteria eksklusi ialah ibu dengan anak baduta yang memiliki riwayat BBLR dan saat wawancara mengalami permasalahan gizi. Jumlah seluruh informan sebanyak 12 ibu yang memenuhi kriteria dari sebanyak 20 ibu yang memiliki anak baduta dengan riwayat BBLR.

Proses analisis dilakukan melalui beberapa tahap yaitu hasil wawancara dituangkan dalam bentuk transkrip hasil wawancara. Selanjutnya dari hasil transkip dilakukan reduksi jawaban ke dalam subtema tertentu sesuai topik pertanyaan dan dimasukan dalam matriks. Tahap selanjutnya dari hasil pengelompokan berdasarkan subtema dilakukan triangulasi antar peneliti yaitu peneliti yang terlibat dalam penelitian ini membaca hasil wawancara yang telah dikelompokkan menjadi subtema, kemudian membandingkan hasil temuan dari masing-masing peneliti lalu ditarik kesimpulan. Triangulasi antar peneliti merupakan salah satu cara untuk mendapatkan validitas data dalam penelitian kualitatif. ${ }^{16}$

\section{HASIL}

Penelitian ini memperlihatkan praktik IMD, pemberian ASI eksklusif dan pola pemberian makan pada anak baduta dengan riwayat BBLR.

\section{Karakteristik Informan}

Informan merupakan ibu yang memiliki anak usia baduta dengan status gizi normal yang memiliki riwayat BBLR. Rentang berat lahir bayi ialah 1600-2400 gram, dengan jumlah yang 
terbanyak ada pada berat 2300 gram.

Karakteristik informan ibu antara lain berusia 18-40 tahun sejumlah 12 orang, memiliki jenjang pendidikan terbanyak pada tingkat SMA(7 orang), dan 8 orang merupakan ibu rumah tangga. Informan juga ada yang bekerja sebagai pembantu rumah tangga, penjaga toko, buruh pabrik, serta ada juga yang berdagang.

\section{Praktik Inisiasi Menyusu Dini (IMD)}

Pemberian ASI merupakan hal yang penting dilakukan segera setelah anak dilahirkan. Pemberian ASI dimulai dengan IMD Pada penelitian ini sebagian besar ibu tidak melakukan IMD pada bayi. Berikut pernyataan yang diungkapkan informan:

"Engga, kan dia dibawa ke ruangan bayi langsung, kan sesar sayanya. Boro boro ditidurin di dada, liat aja langsung engap (sesak)", (Informan M, 32 tahun)

"Ga IMD kan langsung ke inkubator... baru 2 hari setelah melahirkan baru ditelpon sama rumah sakit ibunya suruh kesini" (Informan H, 39 tahun)

Namun ada juga informan yang mengatakan melakukan IMD, ketika bayi lahir, bayi diletakkan di dada setelah lahir dan mencari puting ibu. Kisaran waktu dilakukannya IMD dari beberapa menit hingga paling lama 15 menit. Berikut disampaikan informan:

"iyah langsung, lama juga yah, kata dokter $H$ tuh itu taro di dadanya, taro di dadanya, nyari (puting) giginian. lebih ya, lama juga sih pas udah dioperasi. ada 15 menitan mah." (Informan $\mathrm{R}, 33$ tahun)

"iyah ditaro di sinih, dia nyariin puting, belum dibersihin iya, paling berapa menit sih nggak lama" (Informan ES, 24 tahun)

"Iya dilakukan... pas belom dimandiin pas keluar pake kain dikasih ke saya lagi diciumciumin ke saya. Iya kan saya telanjang yah nyari gitu-gituan si dedenya tapi ngga dapet (puting) si dedenya. Iya sekitar 10 menitan." (Informan E, 37 tahun)

Setelah bayi dibersihkan, seharusnya bayi diberikan ASI kepada ibu agar dapat segera memperoleh ASI. Pemberian ASI sesaat setelah lahir amat menentukan dalam keberhasilan pemberian ASI eksklusif. Namun karena bayi yang dilahirkan informan merupakan bayi BBLR maka penanganan di rumah sakit terkadang menghendaki bayi dirawat lebih lanjut seperti di letakkan di inkubator.

"Waktu bayinya masih dalam inkubator, ga bisa diituin jadi dimasukin botol aja susunya, ga bisa digendong palingan bisa pegang doang." (Informan M, 32 tahun)

"baru 2 hari setelah melahirkan baru ditelpon sama rumah sakit ibunya suruh kesini, Iya sayanya udah pulang tapi anak masih disana diinkubator, itu aja dikirim ASI dipompa aja" (Informan H, 39 tahun)

\section{Pemberian ASI Eksklusif}

Sebagian besar informan mengatakan sudah memberikan susu formula kepada bayi tidak lama setelah lahir. Ada yang diberikan di rumah sakit saat bayi baru lahir seperti dikatakan oleh informan berikut;

"e... ini, pake susu formula kan. Katanya "Ada ASI-nya ga bu" "ada cuman kan sedikit.. Dipompa, iyah.. udah dipompa dikasih ke bidan. Karena udah ga adaan lagi, dikasih susu formula.. Pernah disusuin tapi udah seminggu baru bisa dikeluarin dari inkubator. Di rumah sakit dua minggu lebih" (Informan R, 18 tahun)

"Iya. harus nyari susu ini yang apa, minum susu merk $S$ supaya naik berat badannya supaya naik, kasih susu itu, beli di situ juga. itu berarti kata suster ini harus diinkubator karena kecil terus harus dikasih.... dikasih tau ini harus ditambah susu formula gitu (susu merk S), iyah dokter (yang nyuruh)" (informan N, 47 tahun)

"Langsung nyusuin udah hari kedua... Sebelumnya itu dikasih susu, susu yang penambah berat badan, oh itu masih kalengnya, susu merk N. Cuma satu bulan doang. Satu bulan habis itu" (Informan T, 40 tahun)

"Saya ngasih ke dia (susu formula merk S), pas pulang. nyusuin tapi si air susu teh putihnya kayak air biasa gitu nggak putih kentel gitu nggak, terus dia muntah- muntah kalau abis dikasih susu sayah nih, dikasih susu botol nggak, udah aja sampai sekarang susu botol. Saya sendiri sih nggak ada yang nyuruh" (Informan R, 33 tahun)

Beberapa ibu memberikan susu formula tak lama setelah bayi pulang dari rumah sakit, seperti dikatakan oleh informan berikut ini:

"Susu formula aja. pas di rumah disusuin, tapi dianya nangis melulu, pentil sayanya kecil. jadi dia nyari- nyari ya. kasian jadi langsung dikasih susu botol aja, he em. suami sih di rumah. ya udah susu botol aja katanya gitu" (Informan E, 24 tahun)

Sebagian besar alasan ibu tidak memberikan ASI eksklusif pada bayi dikarenakan ASI yang belum keluar pada saat setelah lahir, kemudian ada juga ibu yang mengatakan karena 
diinkubator maka bayi belum bisa disusui, alasan lainnya ialah karena ibu merasa ASI yang keluar hanya sedikit.

"Ibu 4 hari, 5 hari di situ (di rumah sakit). nungguin turun dulu darah, baru bisa netekin, terpaksa pake susu botol dulu. iya, dobel (ASI dan susu formula), tapi pas 2 minggu udah gak mau dia (ASI), jadi mau netek botol aja" (Informan N, 47 tahun)

"emang ga ASI... Udah berhenti. Air susunya juga udah ga ada lagi. Iyah susu formula dari bayi sampe sekarang dikasih susu sampe ini aja, sampe sebelum makan" (Informan R, 18 tahun)

Informan mengatakan yang menyuruh untuk memberikan susu selain ASI antara lain perawat di rumah sakit, suami, anak dan keluarga. "Di rumah sakit (pas lahir) nyusunya cuman sedikit sih, terus pas itu, tapi pas yang besoknya lagi disuruh susu botol, he eh, suruh (sama bidan) pake merk $S$ " (Informan E, 24 tahun)

"iya, dobel (ASI dan susu formula), tapi pas 2 minggu udah gak mau dia (ASI), jadi mau netek botol aja, kata suami sama kakaknya daripada anak nangis udah susu botol aja" (Informan N, 47 tahun)

"Nyusunya kurang... kata suami juga katanya susunya udah gak ada lagi kasian anaknya minum, ya udah lah dibantu ya ndak apa- apa lah" (Informan T, 40 tahun)

Namun demikian, ada sebagian ibu memberikan ASI sampai 6 bulan kepada bayinya yang dibarengi dengan pemberian susu formula atau makanan lain sebelum anak berusia 6 bulan. Proporsi ASI yang diberikan lebih besar dari pemberian makanan atau minuman yang lain. Seperti diungkapkan oleh informan berikut;

"Susu merk E yah,,,pulang dari rumah sakit cuma sebulan aja abis itu ngga mau sampe dibuang yang dibeli dari rumah sakit. Sampe sekarang sih masih ASI kalau yang ASI aja sampe 6 bulan. Ngga sih ngga pernah katanya jangan... katanya jangan (dikasih kurma dan madu) kata orang sini tetangga, jangan dikasih garam sama gula banyak2" (Informan E, 37 tahun)

Hanya satu ibu yang berhasil memberikan ASI eksklusif sampai usia 6 bulan. Informan $\mathrm{H}$ (39 tahun) mengatakan bahwa ia mengupayakan anaknya diberi ASI walaupun diinkubator dengan cara ASI dipompa dan dikirimkan ke rumah sakit. Berikut petikannya:

"Iya sayanya udah pulang tapi anak masih disana diinkubator, itu aja dikirim ASI dipompa aja, suka anak - anak yang kesana, saya ngompa sendiri, sekali ngirim cuman 1 botol.. pas sampai rumah ASI aja" (Informan H, 39 tahun)

\section{Pola Pemberian Makan}

Pemberian makan anak harus memperhatikan umur anak. Anak yang masih kecil belum kuat untuk mencerna makanan yang terlalu keras. Pada penelitian ini sebagian besar informan memberikan anak makan pada usia 6 bulan dengan menggunakan makanan instan seperti bubur bayi instan. Hal ini seperti yang diungkapkan informan: "Mulai diberi makan umur 6 bulan bubur merk N, bubur bayi tapi encer sama ASI ajah" (Informan D, 32 tahun; anak S, 15 bulan)

"Mulai makan 6 bulan, bubur instan merk $S$, merk $C$, dan merk $F$ " (Informan N, 22 tahun; anak $\mathrm{S}, 16$ bulan)

Perbaikan status gizi anak dapat tercapai dengan pemberian makan yang terjaga frekuensinya. Sebagian besar informan memberikan makan kepada anaknya sebanyak 2-3 kali dalam sehari. Selain makanan utama, anak juga diberikan makanan selingan atau makanan pendamping ASI lainnya seperti buah, makanan ringan, atau susu formula.

"Dulu minum susu satu hari bisa 10 kali, makan bubur susu merk C nya 3 kali, sekali makan setengah saset. kalau sekarang makan nasi 2 kali, sekali makan 1 centong lauknya apa aja kecap aja mau" (Informan, N, 30 tahun; anak R, 13 bulan)

"Enam bulan (mulai makan). pertama pertama dikasi bubur merk M. Kalo nasi tim belum berani kasih, ngasihnya tiga kali sehari. Takarannya itu kan satu sachet di bagi dua gitu. Tujuh bulan dikasih nasi tim. Nasi tim bayem pake wortel . susu formula dilebihin dikit lah.3/4 lah", (Informan N, 22 tahun; anak S, 16 bulan)

Pemberian makanan yang beragam harus dibiasakan diberikan kepada anak. Hasil penelitian menunjukkan bahwa sebagian besar anak diberikan makanan yang beragam dengan tambahan sayur pada makanan utama atau tambahan buah sebagai makanan selingannya. Sebagian besar anak diberikan bubur nasi atau tim yang dimasak sendiri oleh ibunya, jikapun beli ibu responden membeli bubur sehat yang juga dicampur sayur atau membeli buburnya saja yang kemudian ditambahkan sayuran yang telah disiapkan oleh ibu sendiri.

"Mulai makan 6 bulan, bubur instan merk $S$, merk $C$ dan merk $F$, sehari satu bungkus dibagi tiga sampai umur 8 bulan pagi, siang, sore, abis dua sendok kecil sih. He eh, terus dibantu ku susu lagi, ya itu susah makannya sampai sekarang 
juga. Setelah 8 bulan kasih tim, bikin sih. Nggak pernah (beli) sih waktu itu mah, baru setahun baru (beli). Tim kasar diblender, iya pake wortel pake bayem, makannya 2 kali sih siang roti, buah gitu. Cuma pagi sama sore aja. habisnya paling, kadang 4 sendok kecil, pake bayem, ada telor, iya telor rebus, disatuin, he eh, kalau ayam mah sih diblender gitu. Buahnya pepaya, jeruk, pisang. cemilan, biskuit merk R dan N." (Informan N, 22 tahun; anak S, 16 bulan).

"Dikasih makanan yang bikin sendiri, saya usahain, bikin bubur sendiri, jangan yang instan, soalnya ngeliat dia kan beda sama kakakkakaknya. Soalnya kakak nya mah sehat. Harus bikin sendiri ga apa apa....Mungkin kalau bubur instan merk $N$ kan ada pengawetnya, instan lah kata saya gatau kan..sampe sekarang dia mah makannya dikasih hati, telur mau" (Informan M, 32 tahun; anak A, 7 bulan)

Tidak jarang ibu yang menghadapi masalah kesulitan makan pada anaknya. Namun demikian sebagian besar ibu tidak menyerah dan berupaya untuk mengatasi kesulitan makan pada anaknya. Upaya yang dilakukan ibu agar anaknya mau makan antara lain mengajak anaknya berjalanjalan diluar rumah atau sesuai dengan keinginan anak bahkan ada ibu yang mencari 'syareat' agar anak mau makan. Selain itu juga ada ibu yang aktif mencari informasi tentang bagaimana praktek pemberian makan yang baik bagi anak kepada petugas kesehatan.

"Kalau susah makan diajak main ke luar sambil makan "(Informan N, 30 tahun; anak R, 13 bulan)

"Itu ya kayak ngeliatin anak lain, kalau ini kan makan beek bek bek bek, kalau ini kan emut emut... gitu, lama, Cuma harus telaten sabar" (Informan T, 40 tahun; anak N, 11 bulan)

"Saya suka nanya di Puskesmas kan ada dokter gizi, saya tanya, kalau bayi umur 6 bulan itu boleh dikasih bubur ga? Boleh, kata siapa ga boleh, yang ga boleh itu buah, jangan dulu dikasih buah kalau bayi itu, lebih bagus bikin daripada beli kalau buat bayi itu. Karena kalau bikin kan kita gak tau ada bahan pengawetnya atau apa. Boleh pakai penyedap tapi jangan berlebihan, garam aja sedikit, namanya juga makanan bayi, kalau bisa mah jangan dikasih buah dulu, soalnya belum waktunya. Terus saya nanya ke dokternya, anak saya kan umurnya segini, beratnya segini, ini kan gede, ini obesitas bukan? Kata dokternya enggak lah masa obesitas " (Informan M, 32 tahun; anak A, 7 bulan)

\section{PEMBAHASAN}

Pada anak yang lahir BBLR perlu diperhatikan asupannya terutama pada awal kehidupannya karena pemberiannya berbeda dengan anak yang cukup bulan. Fungsi pencernaan, enzim, serta kemampuan mengosongkan lambung pada anak BBLR berbeda, sehingga pemilihan jenis asupan amat penting dan ASI merupakan pilihan paling utama. ${ }^{17}$ WHO juga merekomendasikan ASI eksklusif selama 6 bulan pertama untuk memenuhi kebutuhan gizi bayi $\mathrm{BBLR}^{4}$ dan ini sesuai juga dengan Undang-undang Kesehatan Nomor 36 Tahun 2009 pasal 128 mengenai hak bayi mendapatkan ASI eksklusif kecuali atas indikasi medis. ${ }^{18}$

Air susu ibu yang diberikan secara eksklusif terhadap bayi BBLR memberikan banyak keuntungan, penelitian di Manila, Filipina pada 204 ibu yang memiliki bayi BBLR memperlihatkan bahwa menyusui ASI secara eksklusif selama 6 bulan dapat melindungi anak dari diare, mengurangi kejadian ISPA, mengurangi angka kunjungan ke tenaga kesehatan, serta dapat mengejar pertumbuhan. ${ }^{9}$ Penelitian lain di RS Arifin Achmad Riau pada 279 responden dari daftar rekam medis tahun 2010-2012 menunjukkan ada hubungan yang bermakna antara pemberian ASI eksklusif dengan kenaikan berat badan 2 minggu pertama anak BBLR dibandingkan dengan yang diberi susu formula. ${ }^{19}$

Penelitian ini memperlihatkan sebagian besar anak dengan riwayat BBLR pernah diberi susu formula disamping diberikan ASI. Hal ini disebabkan beberapa faktor antara lain anak yang dilahirkan dirawat di inkubator, dirawat secara terpisah dari ibu, serta ASI belum banyak keluar. Sehingga ibu memberikan ASI beberapa hari setelah bayi dilahirkan. Pemberian ASI yang tidak segera diberikan ini dapat menjadi faktor penyebab kegagalan pemberian ASI eksklusif kepada bayi. Hal ini sejalan dengan hasil penelitian yang dilakukan di 4 kabupaten di Jawa Barat dan 4 kabupaten/kota di Jawa Timur dalam Survei Data Dasar (SDD) ASUH yang dilakukan oleh Pusat Penelitian Keluarga Sejahtera Universitas Indonesia (PUSKA-UI) dan Program for Approppriate Technology in Health (PATH) menemukan bahwa ibu yang tidak memberikan ASI segera setelah lahir memiliki risiko memberikan makanan/minuman prelakteal 1,8 kali sampai 5,3 kali lebih besar dibandingkan ibu yang memberikan ASI segera setelah lahir. Hasil lainnya juga memperlihatkan bahwa ibu yang segera menyusui bayi setelah lahir memiliki 
kemungkinan 2 sampai 8 kali untuk memberikan ASI secara eksklusif sampai 4 bulan dibandingkan dengan ibu yang tidak menyusui segera setelah lahir. ${ }^{20}$

Selain itu, faktor pendukung seperti praktik IMD juga menjadi hal yang penting suksesnya pemberian ASI eksklusif. Inisiasi menyusu dini memberikan manfaat yaitu merangsang keluarnya hormon oksitosin yang kemudian akan menyebabkan kontraksi otot pada areola payudara ibu sehingga kemudian terjadi let down reflex sehingga ASI akan keluar mengalir ke mulut bayi. ${ }^{21}$ IMD juga dapat mempermudah bayi untuk menyusu ASI pada ibu dan mendukung upaya pemberian ASI eksklusif. Penelitian yang dilakukan secara kualitatif di Puskesmas Kecamatan Jagakarsa terhadap 14 orang ibu memperlihatkan bahwa praktik IMD merupakan faktor penguat yang memungkinkan keberhasilan pemberian ASI eksklusif. ${ }^{22}$ Penelitian terhadap 80 bayi berusia 7-10 bulan di Kabupaten Sragen juga menunjukkan bahwa IMD berhubungan bermakna dengan pemberian ASI eksklusif. ${ }^{23}$ Kementerian Kesehatan juga telah meletakkan IMD sebagai salah satu perawatan bayi baru lahir yang harus dilakukan selama satu jam pertama setelah kelahiran..$^{24}$

Penelitian ini menunjukkan bahwa sebagian besar informan tidak melakukan IMD ataupun jika melakukan namun kurang tepat. Hal ini sejalan dengan penelitian di 6 negara (Kenya, Zambia, India, Pakistan, Argentina dan Guatemala) yaitu salah satu faktor penghambat dilakukannya IMD ialah BBLR. ${ }^{25}$ Penelitian lain di India memperlihatkan pada bayi dengan berat lahir rendah waktu dimulainya IMD lebih lama dibandingkan dengan bayi yang lahir dengan berat normal. ${ }^{26}$

Tidak dilakukannnya IMD berkaitan dengan tidak diberikannya ASI secara eksklusif oleh ibu kepada bayi. Hal ini juga terlihat pada hasil penelitian, sebagian besar ibu tidak memberikan ASI secara eksklusif kepada bayinya namun memberikan ASI disertai susu formula. Pemberian susu formula selain ASI pada bayi BBLR memang dimungkinkan jika memang bayi memiliki masalah medis serta ASI ibu dianggap tidak mencukupi. Hasil penelitian di RS Pirngadi Medan pada bayi prematur yang BBLR memperlihatkan bahwa pada 38 bayi yang diteliti, yang mendapatkan susu pengganti ASI dan campuran susu pengganti ASI memiliki peningkatan berat badan yang bermakna secara statistik dibandingkan hanya yang mendapatkan ASI saja. ${ }^{27}$ Dari penelitian lain menunjukkan bahwa bayi yang mendapatkan asupan susu formula mengalami kenaikan berat badan yang cenderung cepat dibandingkan dengan hanya diberikan ASI namun kemudian cenderung mengalami kelebihan berat badan. ${ }^{28}$ Selain memiliki risiko mengalami obesitas, pemberian susu formula BBLR terlalu dini pada bayi BBLR dapat meningkatkan tingkat kesakitan (morbiditas). ${ }^{29}$

Hal yang lain yang mendukung pemberian ASI eksklusif ialah kebijakan tempat bersalin atau rumah sakit untuk berkomitmen merawat gabung bayi dan ibu serta dukungan terhadap pemberian ASI eksklusif amat berpengaruh terhadap keberhasilan pemberian ASI eksklusif. Berdasarkan penelitian ini terlihat bahwa sejak dari awal bayi lahir di tempat bersalin atau rumah sakit sudah diperkenalkan dengan susu formula, padahal bayi yang sudah berkenalan dengan susu formula biasanya enggan memilih ASI karena rasa manis dan aroma dari susu formula. ${ }^{28}$

Faktor pendukung pemberian ASI sangat dipengaruhi oleh dukungan keluarga terutama suami. Penelitian yang dilakukan di Padang memperlihatkan bahwa ibu yang mendapatkan dukungan suami berpeluang 2 kali untuk memberikan ASI eksklusif dibandingkan dengan ibu yang tidak mendapatkan dukungan suami. ${ }^{30}$ Pada penelitian lain di Pasuruan, memperlihatkan motivasi suami yang positf berhubungan dengan Sikap ibu dalam melaksanakan ASI eksklusif. ${ }^{31}$

Pola asuh merupakan faktor tidak langsung yang mempengaruhi status gizi anak. Berdasarkan WHO, pola asuh makan yang baik pada anak mencakup pemberian inisiasi menyusu dini, ASI ekslusif, umur pertama kali disusui yang idelanya pada saat bayi berusia 6 bulan, memberikan ASI hingga 2 tahun, pemberian makanan yang beragam, dan frekuensi makan yang cukup sesuai umur. ${ }^{32}$ Pemberian makan yang terlalu dini, sebelum bayi berusia 6 bulan, dapat berisiko menyebabkan gangguan pencernaan pada bayi seperti diare atau mencret. Sehingga pemberian makanan harus dimulai pada usia yang tepat. Hasil penelitian menunjukkan bahwa umur pertama kali makan saat 6 bulan mengurangi risiko wasting pada anak umur 6-23 bulan. ${ }^{33}$ Penelitian di Ghana juga menunjukkan bahwa pengenalan makanan pendamping ASI (MPASI) pada usia 6 bulan atau lebih dapat menurunkan risiko kekurangan gizi kronis. ${ }^{34}$

Frekuensi makan merupakan salah satu proxy atau gambaran asupan energi diluar ASI. Frekuensi makanan yang disarankan oleh WHO 
adalah 2 kali sehari diberikan MPASI untuk umur 6-8 bulan, 3 kali sehari diberikan MP ASI untuk anak umur 9-23 bulan, dan 4 kali sehari untuk anak 6-23 bulan yang tidak diberi ASI. ${ }^{31}$ Hasil penelitian ini menunjukkan bahwa frekuensi pemberian makan kepada anak cenderung sesuai dengan anjuran dari WHO.

Pemberian makanan yang beragam akan meningkatkan asupan gizi makro maupun mikro yang dibutuhkan oleh tubuh anak untuk pertumbuhan optimal. Terdapat tujuh jenis kelompok makanan yang digunakan untuk mengukur keragaman makanan anak yaitu umbiumbian, kacang-kacangan, susu dan produk susu, daging, telur, sayuran dan buah kaya vitamin A, dan sayur dan buah lainnya. ${ }^{32}$ Hasil penelitian ini menunjukkan bahwa sebagian besar anak dapat mengejar status gizi yang baik karena sebagian besar anak mengonsumsi makanan yang cenderung beragam. Hasil penelitian menunjukkan bahwa konsumsi makanan yang beragam $>4$ grup pada anak umur 6-23 bulan dapat mengurangi kejadian wasting. ${ }^{33}$ Namun demikian pola asuh anak berhubungan dengan situasi keluarga seperti sumber daya yang dimiliki dan juga pola asuh dipengaruhi karakteristik pengasuh seperti pendidikan, pengetahuan, budaya, dan lainnya.

Penelitian ini memiliki keterbatasan, yaitu hanya memberikan gambaran praktik IMD, pemberian ASI eksklusif dan pemberian makan pada baduta yang memiliki status gizi normal dengan riwayat BBLR, tidak dapat memberi gambaran dan tidak dapat dibandingkan dengan anak yang gagal tumbuh yang memiliki riwayat BBLR. Selain itu keterbatasan lainnya ialah peneliti tidak melakukan penggalian jumlah zat gizi yang dikonsumsi anak. Penelitian ini dilakukan saat anak sudah berusia baduta, sehingga ada bias ingatan walaupun sudah dilakukan antisipasi dengan mengajukan beberapa pertanyaan yang berbeda tetapi bertujuan menjawab subtema yang sama.

\section{KESIMPULAN}

Penelitian ini menunjukkan bahwa sebagian besar informan tidak melakukan IMD dan juga memberikan ASI disertai susu formula. Namun pada pola pemberian makanan sebagian besar memperlihatkan bahwa frekuensi pemberian makan kepada anak cenderung sesuai, Memberikan makanan dengan frekuensi yang sesuai dan beragam merupakan salah satu faktor yang mendukung tercapainya status gizi yang normal pada anak baduta yang memiliki riwayat BBLR.

\section{SARAN}

Perlunya dilakukan promosi kesehatan untuk meningkatkan pangetahuan ibu tentang frekuensi dan jenis makanan yang beragam. Serta memperkuat peran fasilitas pelayanan kesehatan dan dukungan nakes dalam melaksanakan praktik IMD. Selain itu, diperlukan promosi kesehatan tentang pentingnya dukungan keluarga dalam pemberian ASI eksklusif juga masih perlu ditingkatkan.

\section{UCAPAN TERIMA KASIH}

Penulis mengucapkan terima kasih kepada DR. Anies Irawati, M.Kes. selaku ketua pelaksana penelitian Kohor Tumbung Kembang Anak, yang telah memberikan kesempatan untuk melakukan studi kualitatif yang merupakan bagian dari penelitian kohor Tumbuh Kembang Anak tahun 2017. Penulis juga mengucapkan terima kasih kepada tim yang terlibat serta para informan yang telah berpartisipasi dalam studi ini.

\section{DAFTAR PUSTAKA}

1. BKKBN, BPS, Kemkes, ICF. Survei demografi dan kesehatan 2017. Jakarta: BKKBN; 2013.

2. Liu L, Johnson HL, Cousens S, Perin J, Scott S, Lawn JE, et al. Global, regional, and national causes of child mortality: an updated systematic analysis for 2010 with time trends since 2000. Lancet [Internet]. 2012 Jun 9 [cited 2018 Sep 27];379(9832):2151-61. Available from: http://www.ncbi.nlm.nih.gov/ pubmed/22579125.

3. Badan Penelitian dan Pengembangan Kesehatan. Laporan Riset Kesehatan Dasar Tahun 2013. Jakarta: Badan Penelitian dan Pengembangan Kesehatan; 2013.

4. WHO. Optimal feeding of low birth-weight infants in low-and middle-income countries [Internet]. 2011 [cited 2018 Sep 27]. Available from: http://www.who.int/maternal_child_ adolescent/documents/9789241548366.pdf.

5. Barker DJ, Forsén T, Uutela A, Osmond C, Eriksson JG. Size at birth and resilience to effects of poor living conditions in adult life: longitudinal study. BMJ [Internet]. 2001 Dec 1 [cited 2018 Sep 27];323(7324):1273-6. Available from: http://www.ncbi.nlm.nih.gov/ pubmed/11731388.

6. WHO. Indicators for assessing infant and young child feeding practices: conclusions of a consensus meeting held 6-8 November 
2007 in Washington DC, USA. [internet]. Geneva; 2008[cited 2018 Oct 23]. available from:http://apps.who.int/iris/bitstream/ handle/10665/43895/9789241596664_eng. pdf? sequence $=1$.

7. Presiden Republik Indonesia. Peraturan Pemerintah Nomor 33 Tahun 2012 tentang Pemberian Air Susu Ibu Eksklusif [Internet]. 33 2012. Available from: http://pergizi.org/ images/stories/downloads/PP/pp 332012 ttg pemberian asi ekslusif.pdf.

8. Singh D, Devi N, Raman TR. Exclusive Breast Feeding in Low Birth Weight Babies. Med journal, Armed Forces India [Internet]. 2009 Jul [cited 2018 Sep 27];65(3):208-12. Available from: http://www.ncbi.nlm.nih.gov/ pubmed/27408247.

9. Agrasada G V, Ewald U, Kylberg Phd E, Gustafsson J. Exclusive breastfeeding of low birth weight infants for the first six months: infant morbidity and maternal and infant anthropometry [Internet]. Vol. 20, Asia Pac J Clin Nutr. 2011 [cited 2018 Sep 27]. Available from:http://apjen.nhri.org.tw/server/ APJCN/20/1/62.pdf.

10. Oloyede Oladeji M. Exclusive breastfeeding of babies with low birth weight as a correlate of child survival strategies in the university college hospital, ibadan nigeria [Internet]. Vol. 1, International Journal of Education and Research. 2013 [cited 2018 Sep 28]. Available from: www.ijern.com.

11. Lok K, Chau P, Fan H, Chan K, Chan B, Fung $\mathrm{G}$, et al. Increase in weight in low birth weight and very low birth weight infants fed fortified breast milk versus formula milk: a retrospective cohort study. Nutrients [Internet]. 2017 May 20 [cited 2018 Oct 1];9(5):520. Available from: http://www.mdpi.com/20726643/9/5/520.

12. Kementerian Kesehatan. Buku saku pelayanan kesehatan neonatal esensial [Internet]. Jakarta; 2010 [cited 2018 Sep 1]. Available from: http://kesga.kemkes.go.id/images/pedoman/ Buku-Saku-Pelayanan-Kesehatan-NeonatalEsensial.pdf.

13. Black RE, Victora CG, Walker SP, Bhutta ZA, Christian P, de Onis M, et al. Maternal and child undernutrition and overweight in low-income and middle-income countries. Lancet (London, England) [Internet]. 2013 Aug 3 [cited 2018 Sep 27];382(9890):427-51. Available from: http://www.ncbi.nlm.nih.gov/ pubmed/23746772.
14. Permatasari TAE, Syafruddin A. Early initiation of breastfeeding related to exclusive breastfeeding and breastfeeding duration in rural and urban areas in Subang, West Java, Indonesia. J Heal Res [Internet]. 2016 [cited 2018 Sep 28];30(5):337-45. Available from: https://www.tci-thaijo.org/index.php/ jhealthres/article/view/77866.

15. Anggraini DI, Septira S. nutrisi bagi bayi berat badan lahir rendah (BBLR) untuk Mengoptimalkan Tumbuh Kembang. J Major [Internet]. 2016 Sep 1 [cited 2018 Sep 27];5(3):151-5. Available from: http://juke. kedokteran.unila.ac.id/index.php/majority/ article/view/1053.

16. Farmer T, Robinson K, Elliott SJ, Eyles J. Developing and Implementing a Triangulation Protocol for Qualitative Health Research. Qual Health Res [Internet]. 2006 Mar [cited 2018 Oct 1];16(3):377-94. Available from: http:// www.ncbi.nlm.nih.gov/pubmed/16449687.

17. Nasar SS. Tata laksana nutrisi pada bayi berat lahir rendah. Sari Pediatr [Internet]. 2016 Dec 6 [cited 2018 Sep 27];5(4):165. Available from: https://saripediatri.org/index.php/saripediatri/article/view/915.

18. Presiden Republik Indonesia. UndangUndang Republik Indonesia Nomor 36 Tentang Kesehatan - Indonesian Law No.36 about Health [Internet]. Indonesia; 2009 p. 1-33. Available from: http://www.hukor. depkes.go.id/up_prod_uu/UU No. 36 Th 2009 ttg Kesehatan.pdf.

19. Utami GT. Perbandingan kenaikan berat badan BBLR yang diberi ASI dan susu formula pada dua minggu pertama perawatan. J Online Mhs Bid Ilmu Keperawatan [Internet]. 2014 [cited 2018 Sep 27];1.(1):1-8. Available from: https://www.google.co.id/ search? $q=13 .+$ Utami + GT. $+2014 .+$ Perbandingan + kenaikan + berat + badan $+\mathrm{B}-$ $\mathrm{BLR}+\mathrm{y}$ ang $+\mathrm{diberi}+\mathrm{ASI}+\mathrm{d}$ an $+\mathrm{su}-$ $\mathrm{su}+$ formula+pada+dua+minggu+ pertama + perawatan. $\&$ rlz $=2 \mathrm{C} 1 \mathrm{CH}-$ $\mathrm{VO}$ o n T W 0537 I D 0541 \& o $\mathrm{q}=13 .+$ Utami + GT. $+2014 .+$ Perbandingan + kenaikan+berat+badan+BBLR+yang+

20. Fikawati S, Syafiq A, Gizi J, Masyarakat K, Kesehatan F. Hubungan antara menyusui segera (immediate breastfeeding) dan pemberian ASI eksklusif sampai dengan empat bulan [Internet]. [cited 2018 Sep 27]. Available from: http://www.univmed.org/wpcontent/uploads/2011/02/Sandra.pdf. 
21. Gangal P, Bhagat K, Prabhu S, Nair R. Breast Crawl: Initiation of Breastfeeding by Breast Crawl [Internet]. 2007 [cited 2018 Sep 27]. Available from: https://breastcrawl.org/pdf/ breastcrawl.pdf.

22. Fikawati S, Syafiq A. Penyebab Keberhasilan dan Kegagalan Praktik Pemberian ASI Eksklusif. Kesmas Natl Public Heal J [Internet]. 2009 Dec 1 [cited 2018 Sep 27];4(3):120. Available from: http://journal. fkm.ui.ac.id/kesmas/article/view/184.

23. Sugiarti E, Zulaekah S, Susi Dyah Puspowati D, Karangmalang Kabupaten Sragen P, Gizi Fakultas Ilmu Kesehatan UMS Jl Yani PA, Pos TI, et al. Faktor-faktor yang berhubungan dengan pemberian asi eksklusif di kecamatan karangmalang kabupaten sragen [Internet]. Surakarta; 2011 [cited 2018 Aug 27]. Available from: https://publikasiilmiah.ums. ac.id/bitstream/handle/11617/2948/9. ENI SUGIARTI.pdf;sequence $=1$.

24. Kementerian Kesehatan. Buku saku pelayanan kesehatan ibu di fasilitas kesehatan dasar dan rujukan [Internet]. Jakarta; 2013 [cited 2018 Aug 27]. Available from: http://www.searo. who.int/indonesia/documents/976-602-235265-5-buku-saku-pelayanan-kesehatan-ibu. pdf?ua $=1$.

25. Patel A, Bucher S, Pusdekar Y, Esamai F, Krebs NF, Goudar SS, et al. Rates and determinants of early initiation of breastfeeding and exclusive breast feeding at 42 days postnatal in six low and middle-income countries: A prospective cohort study. Reprod Health [Internet]. 2015 [cited 2018 Sep 28];12 Suppl 2(Suppl 2):S10. Available from: http://www.ncbi.nlm.nih.gov/ pubmed/26063291.

26. Badaya N, Jain S, Kumar N. Time of initiation of breastfeeding in various modes of delivery and to observe the effect of low birth weight and period of gestation on initiation of breastfeeding. Int J Contemp Pediatr [Internet]. 2018 Jun 22 [cited 2018 Oct 1];5(4):1509. Available from: http://www.ijpediatrics.com/ index.php/ijcp/article/view/1643.

27. Ariani A, Ilmu D, Anak K. Peningkatan berat badan pada bayi prematur yang mendapat asi, pasi, dan kombinasi ASI-PASI [Internet]. Vol. 40, Majalah Kedokteran Nusantara. 2007 [cited 2018 Sep 27]. Available from: http://repository.usu.ac.id/bitstream/ handle/123456789/18780/mkn-jun2007-40 $\% 283 \% 29$.pdf? sequence=1\&isAllowed=y.
28. Wijayanti LA \& Meilisa C. Perbedaan berat badan bayi usia 6 bulan yang diberikan asi eksklusif dan non asi eksklusif di Desa Keniten Kecamatan Mojo Kabupaten Kediri. J Penelit Kesehat Suara Forikes. 2011;II(4):190-8.

29. Reeves AA, Johnson MC, Vasquez MM, Maheshwari A, Blanco CL. TGF- $\beta 2$, a protective intestinal cytokine, is abundant in maternal human milk and human-derived fortifiers but not in donor human milk. breastfeed med [Internet]. 2013 Dec [cited 2018 Sep 27];8(6):496-502. Available from: http:// www.ncbi.nlm.nih.gov/pubmed/23869537.

30. Ramadani M, Hadi EN. Dukungan suami dalam pemberian ASI eksklusif di wilayah kerja puskesmas air tawar kota Padang, Sumatera Barat. Kesmas Natl Public Heal J [Internet]. 2010 Jun 1 [cited 2018 Sep 27];4(6):269. Available from: http://journal. fkm.ui.ac.id/kesmas/article/view/166.

31. Kurnia Indriyanti Purnamasari. Hubungan motivasi suami dengan sikap ibu menyusui bayi 0-6 bulan dalam melaksanakan ASI Ekslusif. J Keperawatan dan Kebidanan [Internet]. 2017 [cited 2018 Sep 28];6(1). Available from: https://scholar.google.co.id/citations?user $=$ M5eMq2gAAAAJ\&hl=en\#d=gs_md cita-d $\& p=\& u=\% 2$ Fcitations $\% 3$ Fview op\%3Dview_citation\%26hl\%3Den\%26user\%3DM5e-Mq2gAAAAJ\%26citation for_view\%3DM5eMq2gAAAAJ\%3AUeHWp8X0CEIC\%26tzom\%3D-420.

32. Indicators for assessing infant and young child feeding practices. [cited 2018 Jun 6]; Available from:http://apps.who.int/iris/bitstream/ handle/10665/43895/9789241596664_eng. pdf? sequence $=1$.

33. Fekadu Y, Mesfin A, Haile D, Stoecker BJ. Factors associated with nutritional status of infants and young children in Somali Region, Ethiopia: a cross- sectional study. BMC Public Health [Internet]. 2015 Dec 2 [cited 2018 Sep 27];15(1):846. Available from: http://bmcpublichealth.biomedcentral.com/ articles/10.1186/s12889-015-2190-7.

34. Saaka M, Wemakor A, Abizari A-R, Aryee P. How well do WHO complementary feeding indicators relate to nutritional status of children aged 6-23 months in rural Northern Ghana? BMC Public Health [Internet]. 2015 Nov 23 [cited 2018 Sep 27];15:1157. Available from: http://www.ncbi.nlm.nih.gov/ pubmed/26596246. 